\title{
The sporadic sodium layer: a possible tracer for the conjunction between the upper and lower atmospheres
}

\author{
Shican Qiu ${ }^{1,2,3}$, Ning Wang ${ }^{1,4,5}$, Willie Soon ${ }^{6,7}$, Gaopeng $\mathbf{L u}^{2}$, Mingjiao Jia ${ }^{2,3}$, Xingjin Wang ${ }^{2,3}$, Xianghui Xue ${ }^{2,3}$, \\ Tao $\mathbf{L i}^{2,3}$, and Xiankang $\mathrm{Dou}^{2,3}$ \\ ${ }^{1}$ Department of Geophysics, College of the Geology Engineering and Geomatics, Chang'an University, Xi'an, 710054, China \\ ${ }^{2}$ Key Laboratory of Geospace Environment, Chinese Academy of Sciences, University of Science \& Technology of China, \\ Hefei, Anhui, 230026, China \\ ${ }^{3}$ Mengcheng National Geophysical Observatory, School of Earth and Space Sciences, \\ University of Science and Technology of China, Hefei, Anhui, 230026, China \\ ${ }^{4}$ Department of Geophysics, Gravity \& Magnetic Institute of Chang'an University, Xi'an, 710054, China \\ ${ }^{5}$ Key Laboratory of Western China's Mineral Resources and Geological Engineering, China Ministry of Education, \\ Xi'an, 710054, China \\ ${ }^{6}$ Center for Environmental Research and Earth Sciences (CERES), Salem, MA 01970, USA \\ ${ }^{7}$ Institute of Earth Physics and Space Science (ELKH EPSS), 9400, Sopron, Hungary
}

Correspondence: Shican Qiu (scq@ustc.edu.cn) and Xiankang Dou (dou@ustc.edu.cn)

Received: 16 October 2020 - Discussion started: 29 December 2020

Revised: 2 July 2021 - Accepted: 7 July 2021 - Published: 10 August 2021

\begin{abstract}
In this research, we reveal the inter-connection between lightning strokes, reversal of the electric field, ionospheric disturbances, and a sodium layer $\left(\mathrm{Na}_{\mathrm{S}}\right)$, based on the joint observations by a temperature/wind $(T / W$, where the slash means "and") lidar, an ionosonde, an atmospheric electric mill, a fluxgate magnetometer, and the World Wide Lightning Location Network (WWLLN). Our results suggest that lightning strokes could trigger or amplify the formation of an Nas layer in a descending sporadic E layer $\left(E_{S}\right)$, through a mechanism that involves the overturning of the electric field. A conjunction between the lower and upper atmospheres could be established as follows by these interconnected phenomena, and the key processes could be suggested to be: lightning strokes $\rightarrow$ overturning of the electric field $\rightarrow \mathrm{E}_{\mathrm{S}}$ generating Nas.
\end{abstract}

\section{Introduction}

The upper mesosphere-lower thermosphere (MLT) is the interface region for momentum and energy exchanges between the Earth's low atmosphere and outer space. However, on account of the limitations of detection methods, this region re- mains the least known part of our planet's atmosphere (Wang, 2010). Fortunately, the metal layers (especially the sodium layer), which is located between about $80-110 \mathrm{~km}$, could possibly act as a window to detect the MLT parameters by means of fluorescence resonance lidars (Gardner et al., 1986; Gong et al., 2002, 1997). With an active chemical property, a large resonant backscatter cross section, and a high abundance of sodium atoms, the sodium layer has been widely observed and studied all over the world (Marsh et al., 2013; Collins et al., 2002; Plane, 2003, 1999). The sporadic sodium layer (SSL or Nas), with a neutral sodium density that could double within several minutes, is the most fantastic phenomenon observed in the sodium layer. Since first reported in 1978 (Clemesha et al., 1978), many mechanisms, involving meteor injection (Clemesha et al., 1980), a dust reservoir (von Zahn et al., 1987), recombination of ions and electrons in sporadic E layer $\left(E_{S}\right)$ (Cox and Plane, 1998), and hightemperature theory (Zhou et al., 1993), have all been proposed. Because the $\mathrm{Na}_{\mathrm{S}}$ is suggested to have a connection to so many atmospheric parameters, the metric or phenomenon could be appropriate in acting as a tracer for studying the inter-connection between the middle and upper atmospheres. Up to now, a large number of observations have reported a 
diversity of $\mathrm{Na}_{\mathrm{S}}$ features, but the exact mechanism for $\mathrm{Na}_{\mathrm{S}}$ is probably still uncertain (Collins et al., 2002; Cox et al., 1993; Daire et al., 2002; Gardner et al., 1995; Qiu et al., 2015; Zhou and Mathews, 1995; Zhou et al., 1993).

Among all the proposed mechanisms, the $\mathrm{E}_{\mathrm{S}}$ theory is supported by abundant observations and results from numerical simulations (Cox and Plane, 1998; Daire et al., 2002; Dou et al., 2009, 2010; Gardner et al., 1993; Gong et al., 2002; Kane et al., 2001; Kane et al., 1993, 1991; Kirkwood and Nilsson, 2000; Kwon et al., 1988; Mathews et al., 1993; Miyagawa et al., 1999; Nagasawa and Abo, 1995; Nesse et al., 2008; Shibata et al., 2006; Williams et al., 2006). The key process of $\mathrm{E}_{\mathrm{S}}$ theory is the recombination of ions and electrons in the $E_{S}$ layer while descending to lower altitudes (Cox and Plane, 1998; Daire et al., 2002). The $E_{S}$ layer is mainly influenced by the vertical wind shear (Abdu et al., 2003; Clemesha et al., 1998; Haldoupis et al., 2004; Mathews, 1998; Šauli and Bourdillon, 2008; Wakabayashi and Ono, 2005), the geomagnetic field (Resende et al., 2013; Resende and Denardini, 2012; Zhang et al., 2015; Denardini et al., 2016), and the electric field (Abdu et al., 2003; Damtie et al., 2003; Haldoupis et al., 2004; Kirkwood and Nilsson, 2000; Kirkwood and von Zahn, 1991; Macdougall and Jayachandran, 2005; Matuura et al., 2013; Nygren et al., 2006; Parkinson et al., 1998; Takahashi et al., 2015; Voiculescu et al., 2006; Wakabayashi and Ono, 2005; Wan et al., 2001; Wilkinson et al., 1992). In the Northern Hemisphere, the $E_{S}$ layer would descend to a lower altitude in a southward electric field (Abdu et al., 2003; Damtie et al., 2003; Haldoupis et al., 2004; Kirkwood and Nilsson, 2000; Kirkwood and von Zahn, 1991; Macdougall and Jayachandran, 2005; Nygrén et al., 2006; Parkinson et al., 1998; Takahashi et al., 2015; Voiculescu et al., 2006; Wakabayashi and Ono, 2005; Wan et al., 2001; Wilkinson et al., 1992), and observations in the polar cap suggest that the electric field reversal has an influence on the probability of $E_{S}$ occurrences (Macdougall and Jayachandran, 2005).

On the other hand, the atmospheric electric circuit is a closed loop (Driscoll et al., 1992; Jánský and Pasko, 2014; Lv et al., 2004; Roble and Hays, 1979; Rycroft and Harrison, 2012; Rycroft et al., 2000; Suparta and Fraser, 2012; Tinsley, 2000), like a capacitor with a positive plate (e.g., the ionosphere) and a negative plate (e.g., the ground) and a dielectric medium between them (e.g., the neutral atmosphere). Then the global atmospheric electric circuit formed in the capacitor, with the lightning phenomena generating an upward current (with the atmospheric electric field intensity $E<0)$ and returning a downward current $(E>0)$ under fairweather conditions. Nowadays increasing and emerging evidence is pointing to the close link between the upper atmosphere (e.g., the positive plate) and lower atmosphere (e.g., the negative plate) (Harrison et al., 2010; Rycroft, 2006). For example, a thunderstorm occurring in the lower atmosphere is suggested to have a direct impact on the $E_{S}$ layer based on recent observational results (Bortnik et al., 2006; Christos,
2018; Cummer et al., 2009; Curtius et al., 2006; Davis and Johnson, 2005; Davis and Lo, 2008; England et al., 2006; Fukunishi et al., 1996; Girish and Eapen, 2008; Haldoupis et al., 2012; Immel et al., 2013; Kumar et al., 2009; Kuo and Lee, 2015; Lay et al., 2015; Mangla et al., 2016; Maruyama, 2006; Pasko et al., 2002; Rodger et al., 2001; Rycroft, 2006; Sátori et al., 2013; Sentman and Wescott, 1995; Shao et al., 2013; Sharma et al., 2004; Su et al., 2003; Surkov et al., 2006; Yu et al., 2015) or even on the sodium layer (Yu et al., 2017). The possible carriers or phenomena connecting the thunderstorm to the upper atmosphere are suggested to be atmospheric tides (England et al., 2006; Haldoupis et al., 2004; Immel et al., 2013), planetary waves (Lv et al., 2004), gravity waves (Davis and Johnson, 2005; Kumar et al., 2009; Lay et al., 2015; Shao et al., 2013), transient luminous events (TLEs) (Cummer et al., 2009; Fukunishi et al., 1996; Haldoupis et al., 2012; Pasko, 2008; Pasko et al., 2002; Sentman and Wescott, 1995; Sharma et al., 2004; Su et al., 2003), the solar activity (Zhang et al., 2020), and also electric fields (Bortnik et al., 2006; Davis and Johnson, 2005; Davis and Lo, 2008; Immel et al., 2013; Kuo and Lee, 2015; Maruyama, 2006; Rycroft, 2006; Sátori et al., 2013; Shao et al., 2013).

In this research, we apply five joint observations for our case studies and statistical work: (1) one temperature/wind $(T / W$, where the slash means "and") lidar at Hefei $\left(31.8^{\circ} \mathrm{N}, 117.2^{\circ} \mathrm{E}\right)$, providing observations of sodium density, mesopause temperature, and zonal wind; (2) an ionosonde in Wuhan $\left(30.5^{\circ} \mathrm{N}, 114.6^{\circ} \mathrm{E}\right)$, detecting the $\mathrm{E}_{\mathrm{S}}$ and ionospheric echoes in different modes; (3) an atmospheric electric mill $\left(30.5^{\circ} \mathrm{N}, 114.5^{\circ} \mathrm{E}\right)$, giving simultaneous electric field variations; (4) a fluxgate magnetometer $\left(30.5^{\circ} \mathrm{N}, 114.5^{\circ} \mathrm{E}\right)$, probing the $\mathrm{H}, \mathrm{D}$, and $\mathrm{Z}$ magnetic field components; and (5) the World Wide Lightning Location Network (WWLLN), observing the location and power of a lightning stroke. The purpose of this study is to examine the possibility of $\mathrm{Nas}$ acting as a practical, robust tracer for the conjunction between the upper and lower atmospheres. Our results suggest that lightning strokes may have an influence on the lower ionosphere, leading to the occurrence of $\mathrm{Na}_{\mathrm{S}}$, with the atmospheric electric field probably playing an important role.

\section{Observations and results}

\subsection{An Nas event during the overturning of the electric field}

A sporadic sodium layer is detected on the night of 3 June 2013 , by the $T / W$ lidar (Li et al., 2012). The peak density observed by the west beam of the $T / W$ lidar is $8650 \mathrm{~cm}^{-3}$. This Nas event occurs much higher above the centroid height of the sodium layer (normally at about $92 \mathrm{~km}$ ) (Qiu et al., 2016). Figure 1a shows that the sodium density begins to increase at about 13:20 UT, while the largest intensity of 
(a) Sodium Density by T/W Lidar $\quad\left(\mathrm{cm}^{-3}\right)$

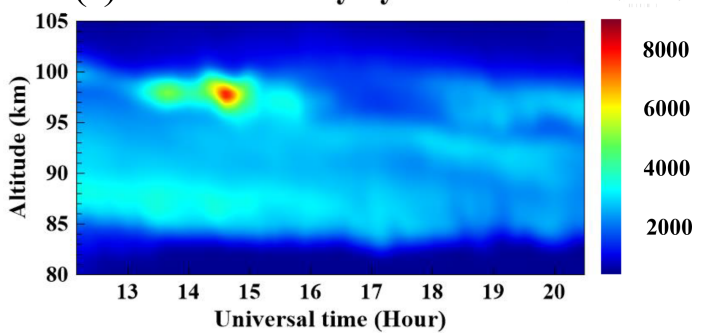

(b) Temperature

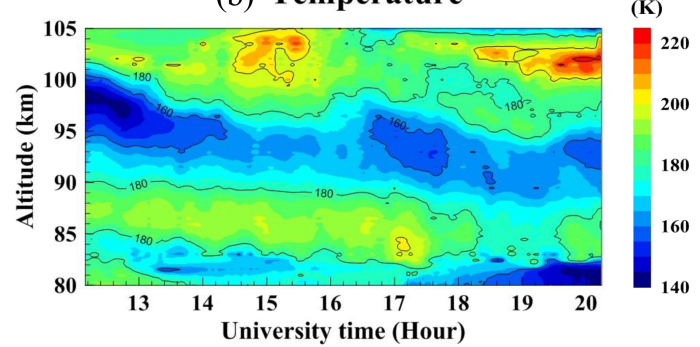

(c) Zonal Wind

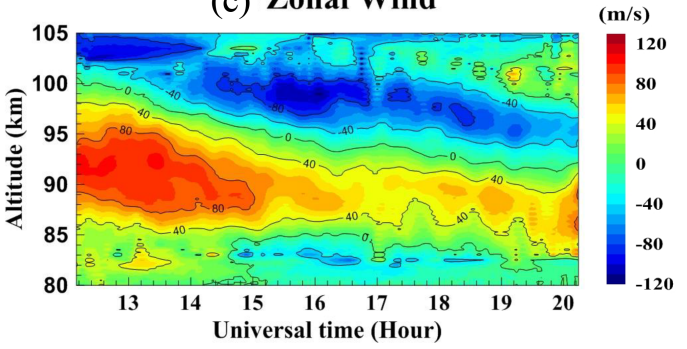

Figure 1. Observations on 3 June 2013, by the $T / W$ lidar of the University of Science \& Technology of China (USTC). (a) The sodium density profile of the west beam by the $T / W$ lidar. A moderate increase in sodium density appears at about 13:20 UT, while the largest intensity of sodium enhancement begins at about 14:20 UT. The sodium density peaks at 14:37 UT around $97.65 \mathrm{~km}$. (b) Temperature profile observed by the $T / W$ lidar, showing a cold region where the Nas occurs. (c) The zonal wind detected by the $T / W$ lidar, exhibiting a suitable wind shear for the creation or formation of $\mathrm{E}_{\mathrm{S}}$.

sodium enhancement occurs from about 14:20 UT, with a peak density located around $97.65 \mathrm{~km}$ at $14: 37 \mathrm{UT}$. The simultaneous temperature observation by the $T / W$ lidar reveals that this Nas occurs in a cold region (Fig. 1b), so the high-temperature mechanism appears to be inapplicable for this event.

On the other hand, the zonal wind exhibits a suitable wind shear for creating those sporadic E layers, with a westward wind above and an eastward wind below (Fig. 1c). The $E_{S}$ layer is predicted to form around the border of the wind shear. Observations by the ionosonde at Wuhan indeed show active sporadic E layers on that day (Fig. 2a and b). The $E_{S}$ series keep traveling/propagating downward starting around 06:30 UT and decreases to a minimum value while the Nas
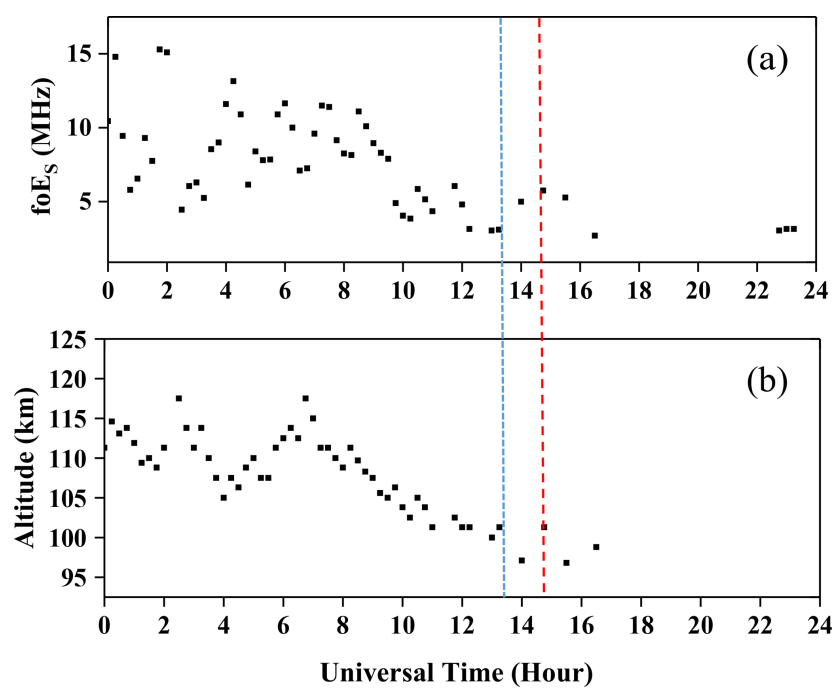

Figure 2. Sporadic E layers observed by the ionosonde at Wuhan $\left(30.5^{\circ} \mathrm{N}, 114.6^{\circ} \mathrm{E}\right)$. (a) The time series of the critical frequency for $\mathrm{E}_{\mathrm{S}}\left(f o \mathrm{E}_{\mathrm{S}}\right)$. The $\mathrm{E}_{\mathrm{S}}$ layers travel/propagate downward starting around 06:30 UT and decreases to a minimum value at about 13:20 UT. (b) The visual height of $\mathrm{E}_{\mathrm{S}}\left(h^{\prime} \mathrm{E}_{\mathrm{S}}\right)$. The blue dotted vertical line shows the beginning of the Nas around 13:20 UT, and the red dashed vertical line indicates the time when the most intense sodium enhancement starts at 14:20 UT.

occurs coincidently at about 13:20 UT. Thus this $\mathrm{Na}_{\mathrm{S}}$ is better explained by the $\mathrm{E}_{\mathrm{S}}$ mechanism, in accordance with our previous study which shows that an $\mathrm{Na}_{\mathrm{S}}$ higher than $96 \mathrm{~km}$ tends to be controlled by the $\mathrm{E}_{\mathrm{S}}$ mechanism (Qiu et al., 2016). Although the content of sodium ions in $E_{S}$ layers seemed to have insufficient concentration (von Zahn et al., 1989), it has also been proposed that the ions could be effectively concentrated by the wind shear (Clemesha et al., 1999; Cox and Plane, 1998; Nesse et al., 2008). On the other hand, laboratory results show that the ligand complexes of $\mathrm{Na}^{+} \cdot X$ would form and thus speed up the recombination of ions in mesopause conditions (Collins et al., 2002; Cox and Plane, 1998; Daire et al., 2002). The calculated reaction rate suggests that the formation of cluster ions is enhanced at lower temperatures, in accordance with the cold region observed in Fig. 1c where the sporadic sodium layer occurs.

More details about the atmospheric parameters are shown in Fig. 3. The time series of sodium density on the peak height display a sharp enhancement from 14:20 UT (marked by the red dashed vertical line in Fig. 3a). The atmospheric electric field detected by the mill exhibits an overturning at around 14:20 UT, alternating from a downward direction to upward (Fig. 3b). It can be clearly observed that the enhancement of sodium density occurs coincidentally with the overturning of the electric field, as highlighted by the red dashed vertical line in Fig. 3. A nearby fluxgate magnetometer provides the horizontal magnetic field $H$ (nT) (Fig. 3c), showing disturbances at 14:15 UT. The total magnetic inten- 


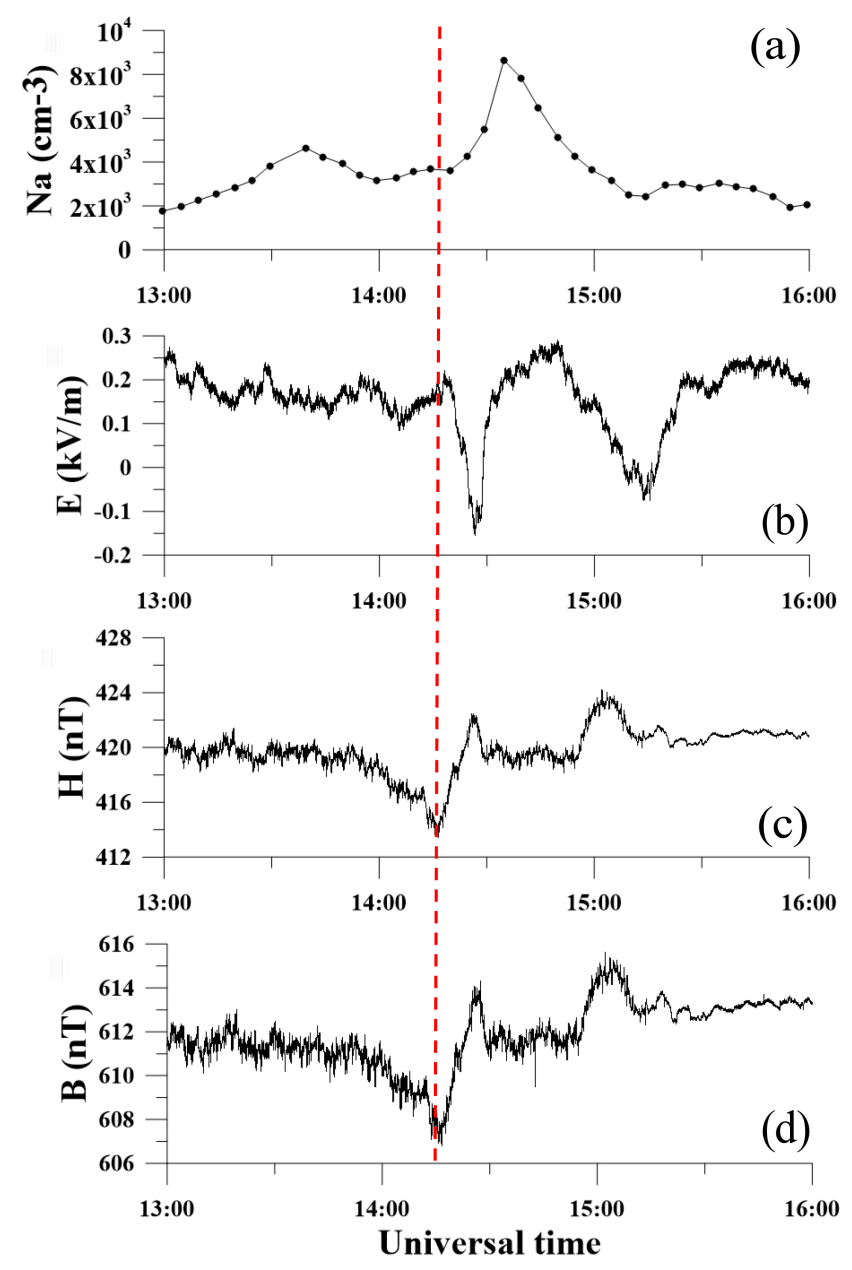

Figure 3. Observations of some atmospheric parameters and some deduced results. (a) Time series of sodium density variations at peak height $97.65 \mathrm{~km}$, observed by the west beam of the $T / W$ lidar. The sodium density begins to increase at about 14:20 UT. (b) Atmospheric electric field variations, exhibiting a synchronous overturning from 14:20 UT with the enhancement of sodium density (also indicated by the red dashed vertical line). Note that there is another overturning peaking at 15:15 UT, without another $\mathrm{Na}_{S}$ being produced, which could be explained by a depletion of ions in the $E_{S}$. The electric field recovers at about 15:30 UT. (c) Horizontal magnetic field observed by the fluxgate magnetometer. (d) The deduced magnetic induction intensity from observations of $H, D$, and $Z$ components by the fluxgate magnetometer $\left(B=\sqrt{H^{2}+D^{2}+Z^{2}}\right)$.

sity $B$ could be deduced by the $H, Z$, and $D$ components $\left(B=\sqrt{H^{2}+D^{2}+Z^{2}}\right)$ from fluxgate magnetometer observations (the calculated values are plotted in Fig. 3d).

It is worth noting that the overturning of atmospheric electric field discussed here is theoretically rough, since the electric field at the lower ionosphere will be modulated as well (e.g., with a value of several $\mathrm{mV} \mathrm{m}^{-1}$; Seyler et al., 2004). Nevertheless, model simulations from the electrodynamics show that the upward electric field in the upper atmosphere is proportional to the source current in the troposphere (Driscoll et al., 1992) and that the upward current would continue transmitting to the heights of $100-130 \mathrm{~km}$ of the dynamo region where $E_{S}$ occurs most frequently (Rycroft et al., 2012). The model, based on rocket observations, shows that the atmospheric electric field has a similar scale and the same polarity from the ground to the altitude of the ionosphere (Abdu et al., 2003). Thus, the electric field detected by a groundbased mill could reasonably be a reflection of the actual situation in the lower ionosphere, at least for the trends and tendencies of variations.

\subsection{Possible influences by the atmospheric electric circuit}

The atmospheric electric circuit is formed by the ionosphere and ground surface with the dielectric medium (e.g., the neutral atmosphere) sandwiched between them (Driscoll et al., 1992; Harrison, 2020; Jánský and Pasko, 2014; Lv et al., 2004; Roble and Hays, 1979; Rycroft and Harrison, 2012; Rycroft et al., 2000, 2012, 2007; Suparta and Fraser, 2012; Tinsley, 2000). The lightning phenomena and thunderstorms, acting as the electric generator for the circuit, drive an upward current to the ionosphere. In a fair-weather regime, the electric field is directed downward to the earth surface $(E>0)$, making a closed global electric circuit (see Fig. A1 in the Appendix). The electric field could vary through two distinct ways as follows. The first one is the changing magnetic field explained by Faraday's law (e.g., $\nabla \cdot \vec{E}=-\frac{\partial \vec{B}}{\partial t}$ ). However, observations by the fluxgate magnetometer show that there is just a small disturbance of the magnetic field during the overturning of the electric field. The other way is the electrostatic induction following Coulomb's law $\vec{E}=$ $\left.\frac{1}{4 \pi \varepsilon_{0}} \frac{Q}{r^{2}} \hat{r}\right)$. The connection between the lightning stroke and the overturning of the electric field could be explained by the classic thunderstorm charge model through the electric imaging method based on Coulomb's law (i.e., this model could be supported by the classic electrodynamics textbook written by Griffiths, 1999). A typical thundercloud (e.g., pairs of $\left(Q_{1},-Q_{2}\right)$ or $\left(-Q_{3}, Q_{4}\right)$ in Fig. A1), with a dipole of positive charge located above a negative charge part, which would produce an upward electric field toward the ionosphere (see more details in Appendix A).

According to the observations from WWLLN, we find two regions (red ovals A and B in Fig. 4) with heavy lightning activities during the period of the Nas. Before the Nas occurrences, there were only a few powerful lightnings detected within about $25.1-35.8^{\circ} \mathrm{N}$ and $113.8-118.1^{\circ} \mathrm{E}$ during the period of 12:00 to 13:15 UT (just one strong stroke with a power of $43720.25 \mathrm{~kW}$ happening at 12:17 UT, at $25.7229^{\circ} \mathrm{N}$ and $117.3955^{\circ} \mathrm{E}$ ). The continuously strongest lightnings with a power larger than $10^{4} \mathrm{~kW}$ occur from 13:19 to 15:43 UT, mainly concentrating in two areas centered around $35.8^{\circ} \mathrm{N}, 118.1^{\circ} \mathrm{E}$ and $25.1^{\circ} \mathrm{N}, 113.8^{\circ} \mathrm{E}$. After 15:45 UT, no strong strokes were detected again within this 


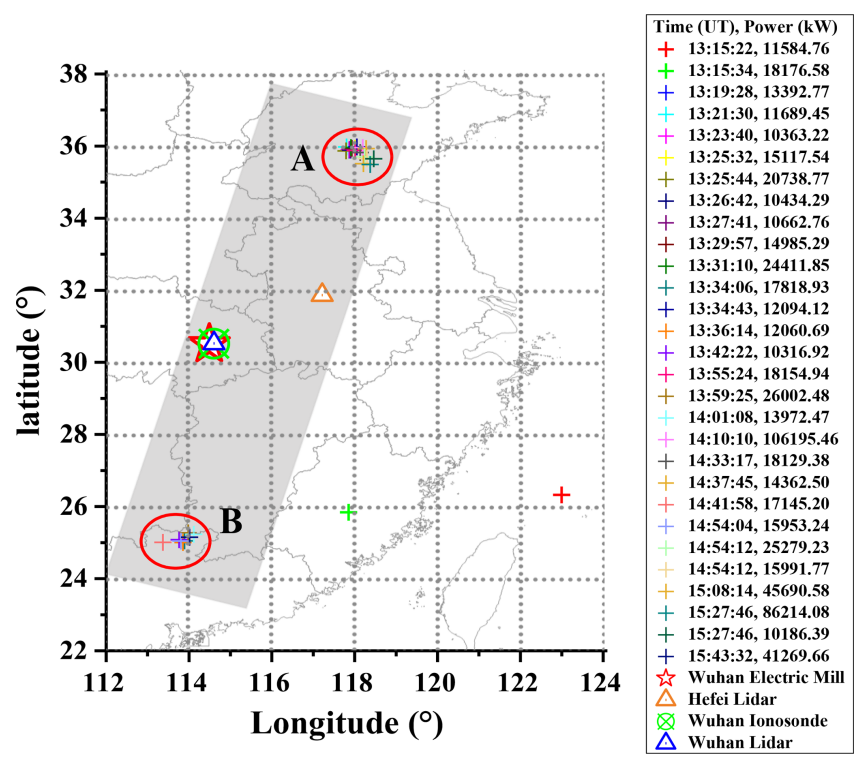

Figure 4. The lightning strokes are detected by WWLLN. The continuously strongest lightnings with a power larger than $10^{4} \mathrm{~kW}$ occur from 13:19 to $15: 43 \mathrm{UT}$, mainly concentrated around areas within $35.8^{\circ} \mathrm{N}, 118.1^{\circ} \mathrm{E}$ and $25.1^{\circ} \mathrm{N}, 113.8^{\circ} \mathrm{E}$.

area. Thus, the pairs of $\left(Q_{1},-Q_{2}\right)$ and $\left(-Q_{3}, Q_{4}\right)$ could refer to the lightning area of part A and B in Fig. 4. Since thunderstorms could trigger the breakdown process within a rather large area (Leblanc et al., 2008) and influence the ionosphere with around more than $800 \mathrm{~km}$ range horizontally away from the lightning center (Johnson and Davis, 2006; Johnson et al., 1999), the whole area above might undergo a breakdown easily around $Q_{1}-Q_{4}$ (e.g., the whole shadow zone in Fig. 4, involving the two strongest lightning areas and the two observing stations).

In previous studies, lightning strokes in the lower atmosphere were reported to cause a reduction of electrons of the ionosphere (Shao et al., 2013) and conversely an enhancement of sodium density in the metal layer (Yu et al., 2017). Those two scenarios are in accordance with our current results presented above, i.e., with a depletion of $E_{S}$ at 13:20 UT and a consequential occurrence of Nas. Although such an idea/picture was proposed a long time ago (Griffiths, 1999), this is the first time that one can apply the imaging method for observing thunderstorms to explain the link between upper and lower atmospheres through an overturning of the upward electric field.

Furthermore, the results from different channels of the Wuhan ionosonde exhibit extraordinary echoes in different modes during the lightning period (Fig. 5a-1). Figure 5ac show that, from 13:15 to $13: 45$ UT, the echoes gradually increase. Note that the powerful lightning period begins at 13:15 UT as well, with the sodium density enhancement occurring at about 13:20 UT. Figure $5 \mathrm{~d}-\mathrm{g}$ show that the most intense echo signals occur during 14:00 to 14:45 UT, while the largest intensity of sodium enhancement begins at 14:20 UT and the sodium density peaks at 14:40 UT. The overturning of the electric field also occurs at 14:20 UT. Figure $5 \mathrm{~h}-\mathrm{j}$ show that, from 15:00 UT to 15:30 UT, the signals weaken gradually; Fig. 5k and 1 show that, the echoes vanish after 15:45 UT. Afterwards, no strong stroke is detected again in the discussed area. Meanwhile, the ionospheric echoes diminish after 15:45 UT, and the overturning of the electric field also recovers at about 15:30 UT. Thus, in this case the ionospheric echoes and the lightning activities exhibit an obvious synchronous behavior.

\section{Discussions}

Normally, the midlatitude $E_{S}$ layers would be brought down gradually by tidal fluctuations (Mathews, 1998). The $\mathrm{E}_{\mathrm{S}}$ theory predicts that when a series of $E_{S}$ layers descend below $100 \mathrm{~km}$, metal ions will be depleted through many chemical reactions involving ions and electrons (Cox and Plane, 1998). The main chemical reactions and corresponding rate coefficients for the sodium species under mesopause conditions are summarized in Table 1 (Cox and Plane, 1998; Jiao et al., 2017; Plane et al., 2015; Plane, 2004; Yuan et al., 2019). The application of reaction branching probabilities to Reactions (R3) to (R11) yields the following first-order rate coefficients for the neutralization rates of $\mathrm{Na}^{+}$ions (Plane, 2004):

$$
\begin{aligned}
& k\left(\mathrm{Na}^{+} \rightarrow \mathrm{Na}\right)=k_{3}\left[\mathrm{~N}_{2}\right][M] \cdot \operatorname{Pr}\left(\mathrm{Na}^{+} \cdot \mathrm{N}_{2} \rightarrow \mathrm{Na}\right)+k_{4}\left[\mathrm{CO}_{2}\right][M]
\end{aligned}
$$

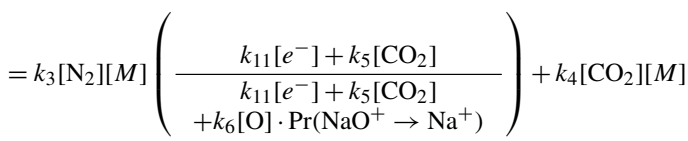

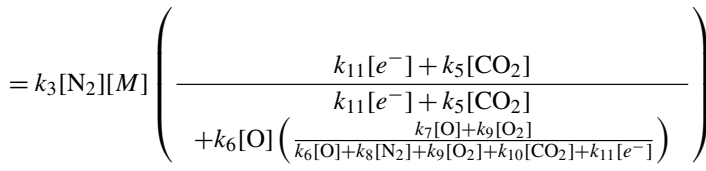

$$
\begin{aligned}
& +k_{4}\left[\mathrm{CO}_{2}\right][M],
\end{aligned}
$$

where $\operatorname{Pr}$ denotes the branching probability. The first-order conversion rate of $k\left(\mathrm{Na}^{+} \rightarrow \mathrm{Na}\right)$ can be computed as a function of height using typical values for $\mathrm{N}_{2}, \mathrm{O}_{2}, \mathrm{O}$, and $\mathrm{CO}_{2}$ from Whole Atmosphere Community Climate Model with Na chemistry (WACCM-Na) (Yuan et al., 2019). The results are given in Fig. 6. The simulation results show that an inflection point of $k\left(\mathrm{Na}^{+} \rightarrow \mathrm{Na}\right)$ comes out at around $100 \mathrm{~km}$, and below that altitude, the sodium ions would recombine with electrons efficiently through cycling chemical reactions under a large $k$ value. Then the production rate of Na could be obtained from $\mathrm{d}[\mathrm{Na}] / \mathrm{d} t=k\left(\mathrm{Na}^{+} \rightarrow \mathrm{Na}\right)\left[\mathrm{Na}^{+}\right]$(Plane, 2004). The number density of electrons $n_{\mathrm{e}}$ could be retrieved through $f o \mathrm{E}_{\mathrm{S}}=\frac{\omega_{\mathrm{pe}}}{2 \pi}=\left(\frac{n_{\mathrm{e}} e^{2}}{4 \pi^{2} m_{\mathrm{e}} \varepsilon_{0}}\right)^{\frac{1}{2}} \approx 9 \sqrt{10^{-6} n_{\mathrm{e}}}$, with $f o \mathrm{E}_{\mathrm{S}}$ in $\mathrm{MHz}$ and $n_{\mathrm{e}}$ in cubic centimeters (Bittencourt, 2004). The $f o \mathrm{E}_{\mathrm{S}}$ observed at $14: 45 \mathrm{UT}$ is equal to $5.75 \mathrm{MHz}$, indicating $n_{\mathrm{e}} \approx 1.24 \times 10^{4} f o \mathrm{ES}^{2}=4.1 \times 10^{5}\left(\mathrm{~cm}^{-3}\right)$. If the pos- 


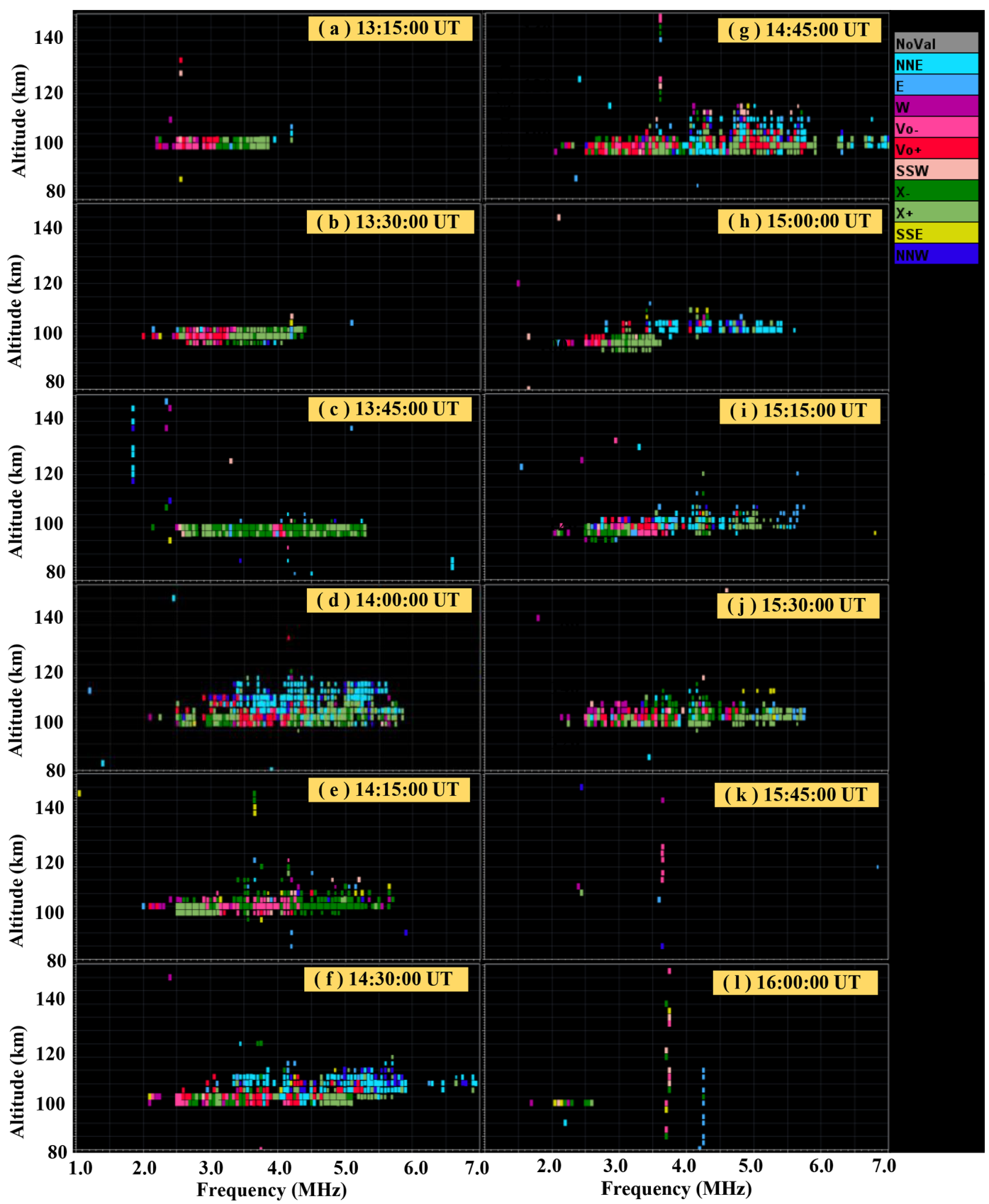

Figure 5. Extraordinary echoes by the Wuhan ionosonde in different modes. (a-c) From 13:15 to 13:45 UT, the echoes gradually increase. Note that the powerful lightning period begins at 13:15 UT as well, with the sodium density enhancement and the $\mathrm{E}_{\mathrm{S}}$ depletion occurring at about 13:20 UT. (d-g) The most intense echo signals occur during 14:00 to 14:45 UT, while the largest intensity of sodium enhancement begins at 14:20 UT and the sodium density peaks at 14:40 UT. The overturning of the electric field also occurs at 14:20 UT. (h-j) From 15:00 to 15:30 UT, the signals weaken gradually. (k-l) The echoes vanish after 15:45 UT. Afterwards, no strong stroke is detected again within the discussed area. Meanwhile, the ionospheric echoes diminish after 15:45 UT, and the overturning of the electric field also recovers at about 15:30 UT.

itive ions are mostly composed of metal ions, with an observed ratio of $\left[\mathrm{Na}^{+}\right]$of $7.41 \times 10^{-2}($ Kopp, 1997), the estimated $\left[\mathrm{Na}^{+}\right]$equates to $3.03 \times 10^{4} \mathrm{~cm}^{-3}$. The approximate value of $k\left(\mathrm{Na}^{+} \rightarrow \mathrm{Na}\right)$ below $100 \mathrm{~km}$ is equal to $10^{-4} \mathrm{~s}^{-1}$. Then the production rate of $\mathrm{Na} \mathrm{d}[\mathrm{Na}] / \mathrm{d} t=k$
$\left(\mathrm{Na}^{+} \rightarrow \mathrm{Na}\right)\left[\mathrm{Na}^{+}\right]$is equal to $3.03 \mathrm{~cm}^{-3} \mathrm{~s}^{-1}$, in accordance with the required source strength of sodium atoms of 3 sodium atoms $\mathrm{cm}^{-3} \mathrm{~s}^{-1}$ for the formation of $\mathrm{Nas}$ (Cox et al., 1993). 
Table 1. Ion-molecule reaction rate coefficients for Na summarized from previous reports (Cox and Plane, 1998; Jiao et al., 2017; Plane et al., 2015, 2004; Yuan et al., 2019).

\begin{tabular}{lll}
\hline No. & Reaction & Rate coefficient* \\
\hline R1 & $\mathrm{Na}+\mathrm{O}_{2}^{+} \rightarrow \mathrm{Na}^{+}+\mathrm{O}_{2}$ & $2.7 \times 10^{-9}$ \\
R2 & $\mathrm{Na}+\mathrm{NO}^{+} \rightarrow \mathrm{Na}^{+}+\mathrm{NO}$ & $8.0 \times 10^{-10}$ \\
R3 & $\mathrm{Na}^{+}+\mathrm{N}_{2}\left(+M=\mathrm{N}_{2} \& \mathrm{O}_{2}\right) \rightarrow \mathrm{Na}^{+} \cdot \mathrm{N}_{2}$ & $4.8 \times 10^{-30}(\mathrm{~T} / 200 \mathrm{~K})^{-2.2}$ \\
R4 & $\mathrm{Na}^{+}+\mathrm{CO}_{2}(+M) \rightarrow \mathrm{Na}^{+} \cdot \mathrm{CO}_{2}$ & $3.7 \times 10^{-29}(\mathrm{~T} / 200 \mathrm{~K})^{-2.84}$ \\
R5 & $\mathrm{Na}^{+} \cdot \mathrm{N}_{2}+\mathrm{CO}_{2} \rightarrow \mathrm{Na}^{+} \cdot \mathrm{CO}_{2}+\mathrm{N}_{2}$ & $6.0 \times 10^{-10}$ \\
R6 & $\mathrm{Na}^{+} \cdot \mathrm{N}_{2}+\mathrm{O} \rightarrow \mathrm{NaO}^{+}+\mathrm{N}_{2}$ & $4.0 \times 10^{-10}$ \\
R7 & $\mathrm{NaO}^{+}+\mathrm{O} \rightarrow \mathrm{Na}^{+}+\mathrm{O}_{2}$ & $1.0 \times 10^{-11}$ \\
R8 & $\mathrm{NaO}^{+}+\mathrm{N}_{2} \rightarrow \mathrm{Na}^{+} \cdot \mathrm{N}_{2}+\mathrm{O}$ & $1.0 \times 10^{-12}$ \\
R9 & $\mathrm{NaO}^{+}+\mathrm{O}_{2} \rightarrow \mathrm{Na}^{+}+\mathrm{O}_{3}$ & $5.0 \times 10^{-12}$ \\
R10 & $\mathrm{NaO}^{+}+\mathrm{CO}_{2} \rightarrow \mathrm{Na}^{+} \cdot \mathrm{CO}_{2}+\mathrm{O}$ & $6.0 \times 10^{-10}$ \\
R11 & $\mathrm{Na}^{+} \cdot \mathrm{X}\left(\mathrm{X}=\mathrm{O}_{2}, \mathrm{NO}_{2}\right)+e^{-} \rightarrow \mathrm{Na}+\mathrm{X}$ & $1.0 \times 10^{-6}(200 \mathrm{~K} / \mathrm{T})^{0.5}$ \\
\hline
\end{tabular}

* Units: bimolecular reactions, $\mathrm{cm}^{3}$ molecule ${ }^{-1} \mathrm{~s}^{-1}$; termolecular reactions, $\mathrm{cm}^{6}$ molecule $\mathrm{e}^{-2} \mathrm{~s}^{-1}$.
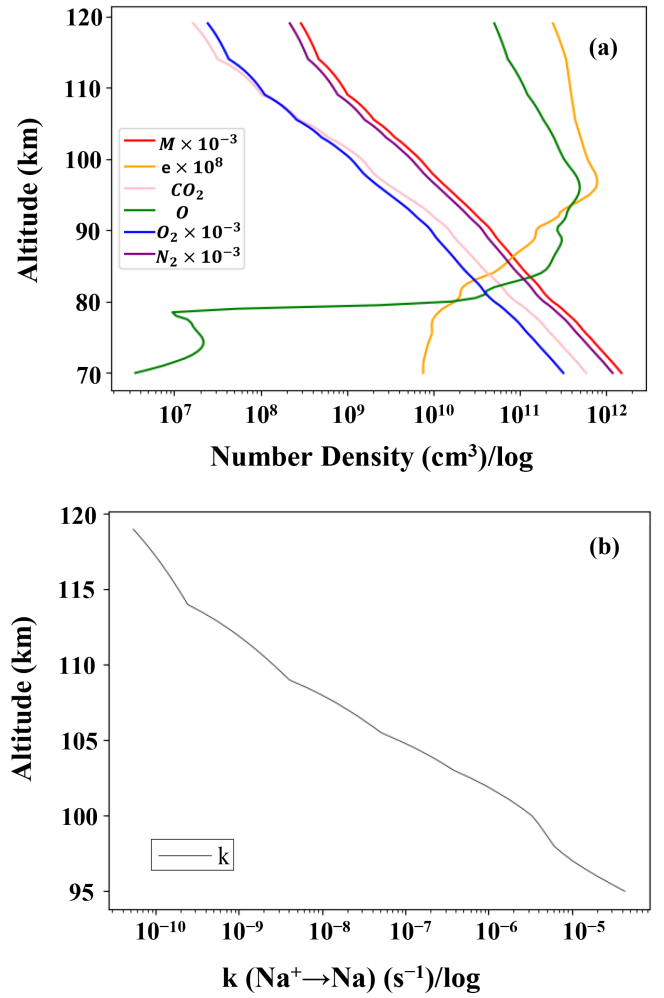

Figure 6. WACCM-Na model simulation results, with the $x$ axis in logarithmic coordinates. (a) Constituents of the species used for calculating $k\left(\mathrm{Na}^{+} \rightarrow \mathrm{Na}\right)$. The number densities of $\mathrm{CO}_{2}, \mathrm{O}_{2}, \mathrm{O}$, the total atmosphere density $M$, and $\mathrm{N}_{2} \approx[M]-\left[\mathrm{O}_{2}\right]-[\mathrm{O}]$ are derived from Yuan et al. (2019). The number density of electrons is equal to $n_{\mathrm{e}} \approx 124 \times 10^{4} f o \mathrm{E}_{\mathrm{S}}{ }^{2}\left(\mathrm{~cm}^{-3}\right)$. (b) The calculated first-order rate coefficient $k\left(\mathrm{Na}^{+} \rightarrow \mathrm{Na}\right)$, indicating much more efficient recombination below about $100 \mathrm{~km}$.
Overall, this $E_{S}$ mechanism is most widely accepted. Figure $2 \mathrm{~b}$ shows $\mathrm{E}_{\mathrm{S}}$ descending near $100 \mathrm{~km}$ at about 13:20 UT. Then the $\mathrm{E}_{\mathrm{S}}$ is depleted, and a moderate enhancement of $\mathrm{Na}$ occurs from 13:30 to 14:00 UT (shown in Figs. 1a and 3a). This increase in sodium density exhibits no obvious peak, which could probably be in accordance with a normally descending $E_{S}$ governed by tides. In comparison, the peak profile of the Nas shows intense enhancement and a sharp peak, indicating a distinct mechanism.

On the other hand, a link between the reverse electric field and $E_{S}$ variations could be established through the acceleration of electrons. In classical electromagnetism, positive particles will move along the direction of the electric field, and negative particles do the opposite (Griffiths, 1999). Since metal ions are much heavier than electrons, the ions would drag electrons to move/drift together; a process known as the bipolar diffusion (Griffiths, 1999). So during the initial phase under quasi-equilibrium conditions, the ions and electrons would co-move downward together along a southward electric field. In a partially ionized plasma, the characteristic frequencies for ions and electrons are associated with the collisions of the plasma particles with stationary neutrals (e.g., the electron-neutral collision frequency $v_{\mathrm{en}}$ and the ion-neutral collision frequency $v_{\text {in }}$ ). The collision frequency $v_{\text {sn }}$ for scattering of the plasma species $s$ by the neutrals is (Shukla and Mamun, 2002)

$v_{\mathrm{sn}}=n_{\mathrm{n}} \sigma_{\mathrm{s}}^{n} V_{T_{s}}$,

where $n_{\mathrm{n}}$ is the neutral number density, $\sigma_{\mathrm{s}}^{n}$ is the scattering cross section (which is typically of the order of $5 \times 10^{-15} \mathrm{~cm}^{2}$ and depends weakly on the temperature $T_{S}$ ) and $V_{T_{s}}=\left(k_{\mathrm{B}} T_{\mathrm{s}} / m_{\mathrm{s}}\right)^{1 / 2}$ is the thermal speed of the species $s$.

Then under a nonequilibrium phase (e.g., at the point of the electric field overturning), each plasma species has a different relaxation time $\tau=\frac{1}{v}$ (the time needed for reestablishing equilibrium again through collisions). The relaxation 
time for ions and electrons would be quite different in a partially ionized plasma with the electrons responding much faster than the heavier sodium ions do (since $m_{\mathrm{i}} \gg m_{\mathrm{e}}$ ). This discrepancy would cause a charge separation temporarily. The single electrons move opposite along the electric field, which means in the upward electric field they would be rapidly accelerated downward, while the ions could be regarded as essentially remaining unchanged. The electrons would reverse rapidly before the ions can respond similarly to the velocity overshoot effect for electrons. During the relaxation phase, the recombination between electrons and ions would probably be triggered through collisions because the relative impact velocity increases and the long-range attraction between the ion and electron becomes less effective.

Based on the above results, a possible mechanism for $\mathrm{Nas}$ could be suggested by the following four steps: (1) strong lightning strokes produce an upward atmospheric electric field toward the ionosphere; (2) the reverse of the electric field would cause a temporary charge separation, leading to a trigger of recombination between electrons and ions; (3) when the $E_{S}$ descends below about $100 \mathrm{~km}$, the sodium ions would recombine with electrons much more efficiently through cycling chemical reactions under a large $k$ $\left(\mathrm{Na}^{+} \rightarrow \mathrm{Na}\right)$ value; (4) the $\mathrm{E}_{\mathrm{S}}$ layers generate the formation of Nas. Thus, we propose that there would probably be a connection between the lightning strokes, the overturning of the electric field, ionospheric disturbances, and also the Nas. A link between the lower and upper atmospheres could be established by carefully studying and examining these phenomena. However, we caution that the key processes for our proposed step (2) still remain quite uncertain. A more indepth modeling study concerning both plasma and neutral molecules is needed in the future.

\section{Conclusions}

In this research, we study the conjunction between the lower and upper atmospheres, through the phenomena and processes of lightning strokes, the overturning of the atmospheric electric field, ionospheric disturbance, plasma drift velocity reversal, and the formation and dissipation of sporadic sodium layer. The main findings of our results are summarized as follows:
1. The Nas event discussed in the present case study shows a close relationship with $E_{S}$ activities rather than conforming to the prescriptions from the competing hightemperature theory.

2. The atmospheric electric field exhibits an overturning, opposite to the fair-weather downward field in the global circuit, coincident with the depletion of $\mathrm{E}_{\mathrm{S}}$ and the consequent production of $\mathrm{Nas}$.

3. A typical thunderstorm, with a positive charge located above a negative charge layer, is shown to produce an upward electric field toward the ionosphere. Two regions with heavy lightning activities nearby are found during the overturning of the atmospheric electric field.

4. Observations by the ionosonde exhibit extraordinary echoes during the lightning period, and the temporal property of the echoes behaved synchronously with lightning activities.

5. WACCM-Na model simulation results show that the calculated first-order rate coefficient $k\left(\mathrm{Na}^{+} \rightarrow \mathrm{Na}\right)$ could probably explain the efficient recombination of $\mathrm{Na}^{+} \rightarrow \mathrm{Na}$ in this $\mathrm{Na}_{\mathrm{S}}$ case study.

Our results support a physical connection between the lightning strokes, the overturning of the electric field, ionospheric disturbances, and possibly the Nas phenomenon as well. A link between the lower and upper atmospheres could be established as follows by the monitoring of $\mathrm{Na}_{S}$ and related phenomena: lightning strokes $\rightarrow$ overturning of the electric field $\rightarrow \mathrm{E}_{\mathrm{S}}$ generating $\mathrm{Na}_{\mathrm{S}}$. 
Appendix A: Calculations for the induced upward electric field in the global electric circuit

Suppose there is positive charge $Q_{1}$ at the top of a thunderstorm, with a distance of $d_{1}$ above the ground and a negative charge $Q_{2}$ at the bottom with a distance of $d_{2}$. Since the ground surface could be regarded as an infinite conducting plane, it would generate an induced charge. The boundary condition here is

$U=0 \quad$ at $\quad z=0$,

$U \rightarrow 0$ at infinity.

Under the uniqueness theorem, we can remove the ground surface if we put the postulated image charges of $-Q_{1}$ and $Q_{2}$ to the corresponding mirror points. Then for an arbitrary point $P$ near the boundary, the vertical electric field is equal to the following expression according to Coulomb's law (Griffiths, 1999):

$E_{\perp}=\frac{1}{4 \pi \varepsilon_{0}}\left[\frac{2 Q_{1} h_{1}}{\left(d_{1}^{2}+h_{1}^{2}\right)^{3 / 2}}-\frac{2 Q_{2} h_{2}}{\left(d_{2}^{2}+h_{2}^{2}\right)^{3 / 2}}\right]$.

In the simplest case, when $Q_{1}$ is equal to $Q_{2}$ and $d_{1}=$ $d_{2}=d, E_{\perp}$ varies with the distance $d$. If $Q_{2}$ is larger than $Q_{1}\left(Q_{2}>Q_{1}>0\right)$ and the negative charge $-Q_{2}$ is closer to the observing point $P\left(d_{2}<d_{1}\right), E_{\perp}$ would acquire negative values (e.g., with the upward direction). A brief simulation result is shown by Fig. A1d, exhibiting persistent negative values for $E_{\perp}$.

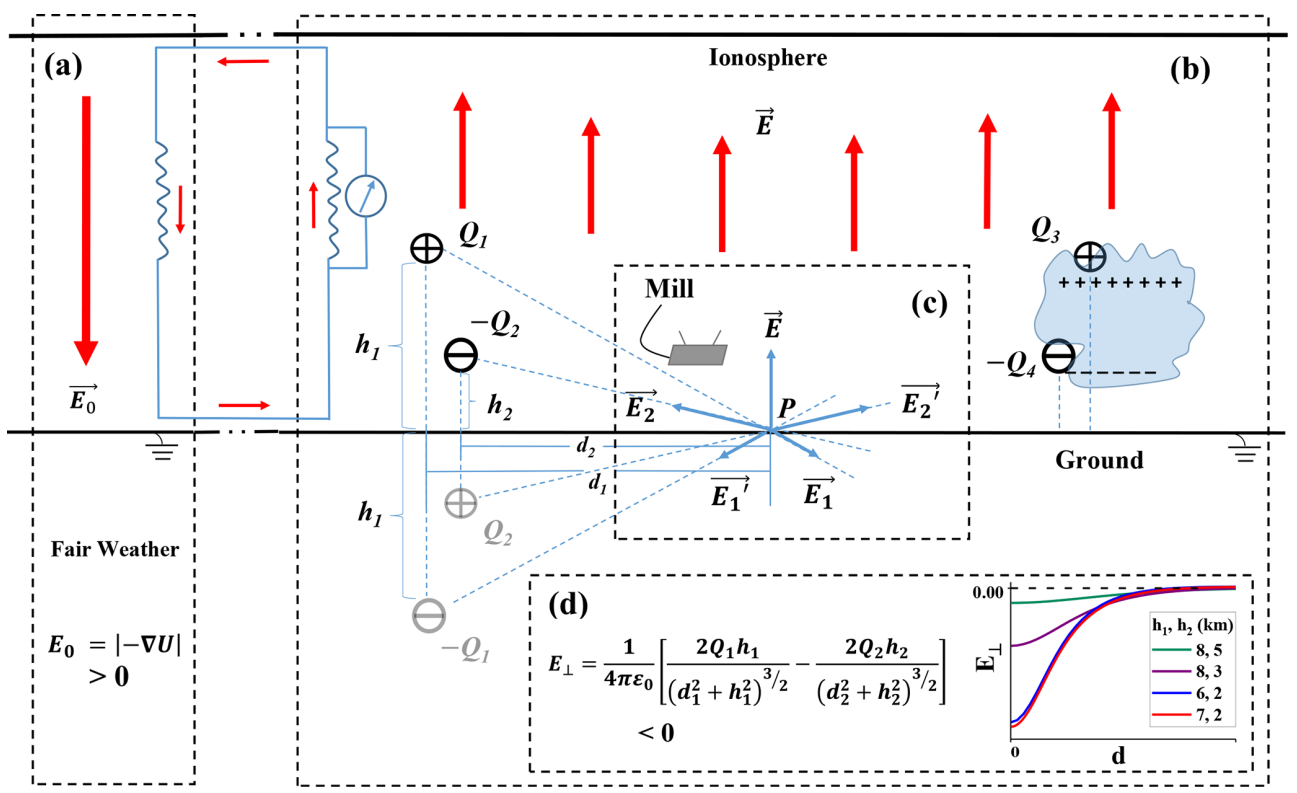

Figure A1. The diagram illustrates the global electric circuit. (a) The atmospheric electric field under fair weather with a downward field returning from the ionosphere. (b) The dynamo area, with thunderstorms generating an upward electric field towards the ionosphere. The electric field intensity $E_{\perp}$ could be deduced through the electric imaging method. (c) The deduced vertical electric field intensity at any point $P$ within the thundercloud. (d) The calculated $E_{\perp}$ based on the electric imaging method. 
Data availability. The data sets of the ionosonde and the fluxgate magnetometer are publicly available from the Chinese Meridian Project database at http://data.meridianproject.ac.cn/ (Chinese Meridian Project, 2021). Observation data of the atmospheric electric field mill at Wuhan Geomagnetic Station is from the National Space Science Data Center, https://doi.org/10.12176/01.05.065 (Wuhan Geomagnetic Station, 2010). The sodium density data of the $T / W$ lidar over Hefei is available from the National Space Science Data Center (https://doi.org/10.12176/01.05.026; University of Science and Technology of China, 2011). The lightning location and power data can be downloaded from the World Wide Lightning Location Network (http://wwlln.net/, WWLLN, 2021).

Author contributions. SQ conceived this study and wrote this paper. She also prepared Figs. $2-5$ in the main text and Fig. A1 in the Appendix. NW performed data analysis. WS was in charge of the organization and polishing the English of the whole paper. GL added some materials about thunderstorms and lightning strokes. MJ prepared Fig. 1 and gave some useful comments on the content. $\mathrm{XW}$ wrote the response to reviewers and calculated the model simulation results. XX wrote the response to reviewers and added some materials in the discussion. TL helped with the response to reviewers. XD conceived this study and provided data from the Chinese Meridian Project.

Competing interests. The authors declare that they have no conflict of interest.

Disclaimer. Publisher's note: Copernicus Publications remains neutral with regard to jurisdictional claims in published maps and institutional affiliations.

Acknowledgements. This work is supported by the National Natural Science Foundation of China (nos. 41974178 and 41831071), the CNSA pre-research Project on Civil Aerospace Technologies (no. D020105), and the National Key R\&D Program of China (no. 2017YFC0602202). We acknowledge the constructive reviews by both referees. Thanks to Wuhu Feng from the University of Leeds, Jianfei Wu from the University of Science \& Technology of China, and Jing Jiao from National Space Science Center for their help on the model simulation. We thank Han Jin and Jin Wang for calibration of the ionograms. The first author would like to thank Hao Chen and Yandong Liu for their help on debugging programs.

Financial support. This research has been supported by the National Natural Science Foundation of China (grant nos. 41974178 and 41831071), the CNSA pre-research Project on Civil Aerospace Technologies (no. D020105), and the National Key R\&D Program of China (grant no. 2017YFC0602202).

Review statement. This paper was edited by Gabriele Stiller and reviewed by two anonymous referees.

\section{References}

Abdu, M. A., Macdougall, J. W., Batista, I. S., Sobral, J. H. A., and Jayachandran, P. T.: Equatorial evening prereversal electric field enhancement and sporadic $\mathrm{E}$ layer disruption: A manifestation of E and F region coupling, J. Geophys. Res.-Space, 108, SIA 8-1SIA 8-13, 2003.

Bittencourt, J. A.: Fundamentals of Plasma Physics, 3rd Edn., Springer-Verlag, New York, Inc., 9-10 pp., 2004.

Bortnik, J., Thorne, R. M., O'Brien, T. P., Green, J. C., Strangeway, R. J., Shprits, Y. Y., and Baker, D. N.: Observation of two distinct, rapid loss mechanisms during the 20 November 2003 radiation belt dropout event, J. Geophys. Res.-Space, 111, A12216, https://doi.org/10.1029/2006JA011802, 2006.

Chinese Meridian Project: available at: http://data.meridianproject. ac.cn/, last access: 6 August 2021.

Christos, H.: Is there a conclusive evidence on lightning-related effects on sporadic E layers?, J. Atmos. Sol.-Terr. Phy., 172, 117121, 2018.

Clemesha, B. R., Kirchhoff, V., Simonich, D. W., and Takahashi, H.: Evidence of an extra-terrestrial source for the mesospheric sodium layer, Geophys. Res. Lett., 5, 873-876, 1978.

Clemesha, B. R, Kirchhoff, V., Simonich, D. W., Takahashi, H., and Batista, P.: Spaced lidar and nightglow observations of an atmospheric sodium enhancement, J. Geophys. Res.-Space, 85, 34803484, 1980.

Clemesha, B. R., Simonich, D. M., Batista, P. P., and Batista, I. S.: Lidar observations of atmospheric sodium at an equatorial location, J. Atmos. Sol.-Terr. Phy., 60, 1773-1778, 1998.

Clemesha, B. R., Batista, P., and Simonich, D.: An evaluation of the evidence for ion recombination as a source of sporadic neutral layers in the lower thermosphere, Adv. Space Res., 24, 547-556, 1999.

Collins, S. C., Plane, J. M. C., Kelley, M. C., Wright, T. G., Soldán, P., Kane, T. J., Gerrard, A. J., Grime,B. W., Rollason, R. J., and Friedman, J. S., González, S. A., Zhou, Q., Sulzer, M. P., and Tepley, C. A.: A study of the role of ion-molecule chemistry in the formation of sporadic sodium layers, J. Atmos. Sol.-Terr. Phy., 64, 845-860, 2002.

Cox, R., Plane, J. M. C., and Green, J. S. A.: A modelling investigation of sudden sodium layers, Geophys. Res. Lett., 20, 28412844, 1993.

Cox, R. M. and Plane, J. M. C.: An ion-molecule mechanism for the formation of neutral sporadic Na layers, J. Geophys. Res., 103, 6349-6359, 1998.

Cummer, S. A., Li, J., Han, F., Lu, G., Jaugey, N., Lyons, W. A., and Nelson, T. E.: Quantification of the troposphere-to-ionosphere charge transfer in a gigantic jet, Nat. Geosci., 2, 617-620, 2009.

Curtius, J., Lovejoy, E. R., and Froyd, K. D.: Atmospheric Ioninduced Aerosol Nucleation, Space Sci. Rev., 125, 159-167, 2006.

Daire, S. E., Plane, J. M. C, Gamblin, S. D., Soldán, P., Lee, E. P. F, and Wright, T. G.: A theoretical study of the ligand-exchange reactions of $\mathrm{Na}^{+} \cdot \mathrm{X}$ complexes $\left(\mathrm{X}=\mathrm{O}, \mathrm{O}_{2}, \mathrm{~N}_{2}, \mathrm{CO}_{2}\right.$ and $\left.\mathrm{H}_{2} \mathrm{O}\right)$ : implications for the upper atmosphere, J. Atmos. Sol.-Terr. Phy., 64, 863-870, 2002.

Damtie, B., Nygrén, T., Lehtinen, M. S., and Huuskonen, A.: High resolution observations of sporadic-E layers within the polar cap ionosphere using a new incoherent scatter radar experiment, 
Ann. Geophys., 20, 1429-1438, https://doi.org/10.5194/angeo20-1429-2002, 2002.

Davis, C. J. and Johnson, C. G.: Lightning-induced intensification of the ionospheric sporadic E layer, Nature, 435, 799-801, 2005.

Davis, C. J. and Lo, K. H.: An enhancement of the ionospheric sporadic -E layer in response to negative polarity cloud-to-ground lightning, Geophys. Res. Lett., 35, L05815, https://doi.org/10.1029/2007GL031909, 2008.

Denardini, C. M., Resende, L. C. A., Moro, J., and Chen, S. S.: Occurrence of the blanketing sporadic E layer during the recovery phase of the October 2003 superstorm, Earth Planets Space, 68, $1-9,2016$

Dou, X. K., Xue, X. H., Li, T., Chen, T. D., Chen, C., and Qiu, S. C.: Possible relations between meteors, enhanced electron density layers, and sporadic sodium layers, J. Geophys. Res.-Space, 115, A06311, https://doi.org/10.1029/2009JA014575, 2010.

Dou, X.-K., Xue, X.-H., Chen, T.-D., Wan, W.-X., Cheng, X.W., Li, T., Chen, C., Qiu, S., and Chen, Z.-Y.: A statistical study of sporadic sodium layer observed by Sodium lidar at Hefei $\left(31.8^{\circ} \mathrm{N}, 117.3^{\circ} \mathrm{E}\right)$, Ann. Geophys., 27, 2247-2257, https://doi.org/10.5194/angeo-27-2247-2009, 2009.

Driscoll, K. T., Blakeslee, R. J., and Baginski, M. E.: A modeling study of the time-averaged electric currents in the vicinity of isolated thunderstorms, J. Geophys. Res.-Atmos., 97, 11535-11551, 1992.

England, S. L., Maus, S., Immel, T. J., and Mende, S. B.: Longitudinal variation of the E-region electric fields caused by atmospheric tides, Geophys. Res. Lett., 33, L21105, https://doi.org/10.1029/2006GL027465, 2006.

Fukunishi, H., Takahashi, Y., Kubota, M., Sakanoi, K., Inan, U, S., and Lyons, W. A.: Elves: Lightning-induced transient luminous events in the lower ionosphere, Geophys. Res. Lett., 23, 21572160,1996

Gardner, C. S., Kane, T. J., Senft, D. C., Qian, J., and Papen, G. C.: Simultaneous observations of sporadic $\mathrm{E}, \mathrm{Na}, \mathrm{Fe}$, and $\mathrm{Ca}^{+}$layers at Urbana, Illinois: Three case studies, J. Geophys. Res.-Atmos., 98, 16865-16873, 1993.

Gardner, C. S., Tao, X., and Papen, G. C.: Observations of strong wind shears and temperature enhancements during several sporadic Na layer events above Haleakala, Geophys. Res. Lett., 22, 2809-2812, 1995.

Gardner, C. S., Voelz, D., Sechrist Jr, C., and Segal, A.: Lidar studies of the nighttime sodium layer over Urbana, Illinois: 1. Seasonal and nocturnal variations, J. Geophys. Res., 91, 1365913673, 1986.

Girish, T. E. and Eapen, P. E.: Geomagnetic and sunspot activity associations and ionospheric effects of lightning phenomena at Trivandrum near dip equator, J. Atmos. Sol.-Terr. Phy., 70, 2222 2232, 2008.

Gong, S., Zeng, X., Xue, X., Zheng, W., Hu, Z., Jia, H., Zhang, H., and Liu, Y.: First time observation of sodium layer over Wuhan, China by sodium fluorescence lidar, Sci. China Ser. A, 40, 12281232, 1997.

Gong, S. S., Yang, G. T., Wang, J. M., Liu, B. M., Cheng, X. W., $\mathrm{Xu}$, J. Y., and Wan, W. X.: Occurrence and characteristics of sporadic sodium layer observed by lidar at a mid-latitude location, J. Atmos. Sol.-Terr. Phy., 64, 1957-1966, 2002.
Griffiths, D. J.: Introduction to Electrodynamics, 3rd edn., PrenticeHall, Upper Saddle River, New Jersey, 121-122 pp., 1999.

Haldoupis, C., Pancheva, D., and Mitchell, N. J.: A study of tidal and planetary wave periodicities present in midlatitude sporadic E layers, J. Geophys. Res., 109, A02302, https://doi.org/10.1029/2003JA010253, 2004.

Haldoupis, C., Cohen, M., Cotts, B., Arnone, E., and Inan, U.: Long-lasting D-region ionospheric modifications, caused by intense lightning in association with elve and sprite pairs, Geophys. Res. Lett., 39, L16801, https://doi.org/10.1029/2012GL052765, 2012.

Harrison, R. G.: Behind the curve: a comparison of historical sources for the Carnegie curve of the global atmospheric electric circuit, Hist. Geo Space. Sci., 11, 207-213, https://doi.org/10.5194/hgss-11-207-2020, 2020.

Harrison, R. G., Aplin, K. L., and Rycroft, M. J.: Atmospheric electricity coupling between earthquake regions and the ionosphere, J. Atmos. Sol.-Terr. Phy., 72, 376-381, 2010.

Immel, T. J., Mende, S. B., Hagan, M. E., Kintner, P. M., and England, S. L.: Evidence of Tropospheric Effects on the Ionosphere, Eos T. Am. Geophys. Un., 90, 69-70, 2013.

Jánský, J. and Pasko, V. P.: Charge balance and ionospheric potential dynamics in time dependent global electric circuit model, J. Geophys. Res.-Space, 119, 10, 2014.

Jiao, J., Yang, G., Wang, J., Feng, W., and Plane, J. M. C.: Observations of Dramatic Enhancements to the Mesospheric K Layer, Geophys. Res. Lett., 44, 12536-12542, https://doi.org/10.1002/2017GL075857, 2017.

Johnson, C. G. and Davis, C. J.: The location of lightning affecting the ionospheric sporadic-E layer as evidence for multiple enhancement mechanisms, Geophys. Res. Lett., 33, L07811, https://doi.org/10.1029/2005GL025294, 2006.

Johnson, M. P., Inan, U. S., Lev-Tov, S. J., and Bell, T. F.: Scattering pattern of lightning-induced ionospheric disturbances associated with early/fast VLF events, Geophys. Res. Lett., 26, 2363-2366, 1999.

Kane, T., Grime, B., Franke, S., Kudeki, E., Urbina, J., Kelley, M., and Collins, S.: Joint observations of sodium enhancements and field-aligned ionospheric irregularities, Geophys. Res. Lett., 28, 1375-1378, 2001

Kane, T. J., Hostetler, C. A., and Gardner, C. S.: Horizontal and vertical structure of the major sporadic sodium layer events observed during ALOHA-90, Geophys. Res. Lett., 18, 1365-1368, 1991.

Kane, T. J., Gardner, C. S., Zhou, Q., Mathews, J. D., and Tepley, C. A.: Lidar, radar and airglow observations of a prominent sporadic $\mathrm{Na}$ /sporadic E layer event at Arecibo during AIDA-89, J. Atmos. Sol.-Terr. Phy., 55, 499-511, 1993.

Kirkwood, S. and Nilsson, H.: High-latitude Sporadic-E and other Thin Layers - the Role of Magnetospheric Electric Fields, Space Sci. Rev., 91, 579-613, 2000.

Kirkwood, S. and von Zahn, U.: On the role of auroral electric fields in the formation of low altitude sporadic- $\mathrm{E}$ and sudden sodium layers, J. Atmos. Sol.-Terr. Phy., 53, 389-407, 1991.

Kopp, E.: On the abundance of metal ions in the lower ionosphere, J. Geophys. Res., 102, 9667-9674, 1997. 
Kumar, V. V., Parkinson, M. L., Dyson, P. L., and Burns, G. B.: The effects of thunderstorm-generated atmospheric gravity waves on mid-latitude F-region drifts, J. Atmos. Sol.-Terr. Phy., 71, 19041915, 2009.

Kuo, C. L. and Lee, L. C.: Ionospheric plasma dynamics and instability caused by upward currents above thunderstorms, J. Geophys. Res.-Space, 120, 3240-3253, 2015.

Kwon, K. H., Senft, D. C., and Gardner, C. S.: Lidar observations of sporadic sodium layers at Mauna Kea Observatory, Hawaii, J. Geophys. Res.-Atmos., 93, 14199-14208, 1988.

Lay, E. H., Shao, X. M., Kendrick, A. K., and Carrano, C. S.: Ionospheric acoustic and gravity waves associated with midlatitude thunderstorms, J. Geophys. Res.-Space, 120, 6010-6020, 2015.

Leblanc, F., Aplin, K. L., Yair, Y., Harrison, R. G., Lebreton, J. P., and Blanc, M. (Eds.): Planetary Atmospheric Electricity, Springer Verlag, New York, 83-101, 2008.

Li, T., Fang, X., Liu, W., Gu, S. Y., and Dou, X. K.: Narrowband sodium lidar for the measurements of mesopause region temperature and wind, Appl. Optics, 51, 5401-5411, 2012.

Lv, D. R., Fan, Y., and Xu, J. Y.: Advances in Studies of the Middle and Upper Atmosphere and Their Coupling with the Lower Atmosphere, Adv. Atmos. Sci., 21, 361-368, 2004.

Macdougall, J. W. and Jayachandran, P. T.: Sporadic E at cusp latitudes, J. Atmos. Sol.-Terr. Phy., 67, 1419-1426, 2005.

Mangla, B., Sharma, D. K., and Rajput, A.: Ion density variation at upper ionosphere during thunderstorm, Adv. Space Res., 59, 1189-1199, 2016.

Marsh, D. R., Janches, D., Feng, W., and Plane, J. M. C.: A global model of meteoric sodium, J. Geophys. Res.-Atmos., 118, 11442-11452, 2013.

Maruyama, T.: Extreme enhancement in total electron content after sunset on 8 November 2004 and its connection with storm enhanced density, Geophys. Res. Lett., 33, L20111, https://doi.org/10.1029/2006GL027367, 2006.

Mathews, J. D.: Sporadic E: current views and recent progress, J. Atmos. Sol.-Terr. Phy., 60, 413-435, 1998.

Mathews, J. D., Zhou, Q., Philbrick, C. R., Morton, Y. T., and Gardner, C. S.: Observations of ion and sodium layer coupled processes during AIDA, J. Atmos. Sol.-Terr. Phy., 55, 487-498, 1993.

Matuura, N., Tsuda, T., and Nozawa, S.: Field-aligned current loop model on formation of sporadic metal layers, J. Geophys. Res.Space, 118, 4628-4639, 2013.

Miyagawa, H., Nakamura, T., Tsuda, T., Abo, M., Nagasawa, C., Kawahara, T. D., Kobayashi, K., Kitahara, T., and Nomura, A.: Observations of mesospheric sporadic sodium layers with the MU radar and sodium lidars, Earth Planets Space, 51, 785-797, 1999.

Nagasawa, C. and Abo, M.: Lidar observations of a lot of sporadic sodium layers in mid-latitude, Geophys. Res. Lett., 22, 263-266, 1995.

Nesse, H., Heinrich, D., Williams, B., Hoppe, U.-P., Stadsnes, J., Rietveld, M., Singer, W., Blum, U., Sandanger, M. I., and Trondsen, E.: A case study of a sporadic sodium layer observed by the ALOMAR Weber Na lidar, Ann. Geophys., 26, 1071-1081, https://doi.org/10.5194/angeo-26-1071-2008, 2008.

Nygrén, T., Aikio, A. T., Voiculescu, M., and Ruohoniemi, J. M.: IMF effect on sporadic-E layers at two northern polar cap sites: Part II - Electric field, Ann. Geophys., 24, 901-913, https://doi.org/10.5194/angeo-24-901-2006, 2006.

Plane, J. M. C.: Atmospheric chemistry of meteoric metals, Chem. Rev., 103, 4963-4984, 2003.

Plane, J. M. C.: A time-resolved model of the mesospheric Na layer: constraints on the meteor input function, Atmos. Chem. Phys., 4, 627-638, https://doi.org/10.5194/acp-4-627-2004, 2004.

Plane, J. M. C., Cox, R. M., and Rollason, R. J.: Metallic layers in the mesopause and lower thermosphere region, Adv. Space Res., 24, 1559-1570, 1999.

Plane, J. M. C., Feng, W., and Dawkins, E.: The Mesosphere and Metals: Chemistry and Changes, Chem. Rev., 115, 4497, https://doi.org/10.1021/cr500501m, 2015.

Parkinson, M. L., Dyson, P. L., Monselesan, D. P., and Morris, R. J.: On the role of electric field direction in the formation of sporadic E-layers in the southern polar cap ionosphere, J. Atmos. Sol.Terr. Phy., 60, 471-491, 1998.

Pasko, V. P.: Blue jets and gigantic jets: transient luminous events between thunderstorm tops and the lower ionosphere, Plasma Phys. Contr. F., 50, 124050, https://doi.org/10.1088/07413335/50/12/124050, 2008.

Pasko, V. P., Stanley, M. A., Mathews, J. D., Inan, U. S., and Wood, T. G.: Electrical discharge from a thundercloud top to the lower ionosphere, Nature, 416, 152-154, 2002.

Qiu, S. C, Tang, Y. H, and Dou, X. K: Temperature controlled icy dust reservoir of sodium: A possible mechanism for the formation of sporadic sodium layers, Adv. Space Res., 55, 2543-2565, 2015.

Qiu, S. C, Tang, Y. H, Jia, M. J, Xue, X. H, Dou, X. K, Li, T., and Wang, Y. H.: A review of latitudinal characteristics of sporadic sodium layers, including new results from the Chinese Meridian Project, Earth-Sci. Rev., 162, 83-106, 2016.

Resende, L. C. A. and Denardini, C. M.: Equatorial sporadic Elayer abnormal density enhancement during the recovery phase of the December 2006 magnetic storm: A case study, Earth Planets Space, 64, 345-351, 2012.

Resende, L. C. A., Denardini, C. M., and Batista, I. S.: Abnormal fbEs enhancements in equatorial Es layers during magnetic storms of solar cycle 23, J. Atmos. Sol.-Terr. Phy., 102, 228-234, 2013.

Roble, R. G. and Hays, P. B.: A Quasi-static model of global atmospheric electricity 2. Electrical coupling between the upper and lower atmosphere, J. Geophys. Res., 84, 7247-7256, 1979.

Rodger, C. J., Cho, M., Clilverd, M. A., and Rycroft, M. J.: Lower ionospheric modification by lightning-EMP: Simulation of the night ionosphere over the United States, Geophys. Res. Lett., 28, 199-202, 2001.

Rycroft, M. J.: Electrical processes coupling the atmosphere and ionosphere: An overview, J. Atmos. Sol.-Terr. Phy., 68, 445-456, 2006.

Rycroft, M. J. and Harrison, R. G.: Electromagnetic AtmospherePlasma Coupling: The Global Atmospheric Electric Circuit, Space Sci. Rev., 168, 363-384, 2012.

Rycroft, M. J., Israelsson, S., and Price, C.: The global atmospheric electric circuit, solar activity and climate change, J. Atmos. Sol.Terr. Phy., 62, 1563-1576, 2000. 
Rycroft, M. J., Odzimek, A., Arnold, N. F., Füllekrug, M., Kulak, A., and Neubert, T.: New model simulations of the global atmospheric electric circuit driven by thunderstorms and electrified shower clouds: The roles of lightning and sprites, J. Atmos. Sol.Terr. Phy., 69, 2485-2509, 2007.

Rycroft, M. J., Nicoll, K. A., Aplin, K. L., and Harrison, R. G.: Recent advances in global electric circuit coupling between the space environment and the troposphere, J. Atmos. Sol.-Terr. Phy., 90-91, 198-211, 2012.

Sátori, G., Rycroft, M. J, Bencze, P., Märcz, F., Bór, J., Barta, V., Nagy, T., and Kovács, K.: An Overview of ThunderstormRelated Research on the Atmospheric Electric Field, Schumann Resonances, Sprites, and the Ionosphere at Sopron, Hungary, Surv. Geophys., 34, 255-292, 2013.

Šauli, P. and Bourdillon, A.: Height and critical frequency variations of the sporadic-E layer at mid-latitudes, J. Atmos. Sol.-Terr. Phy., 70, 1904-1910, 2008.

Sentman, D. D. and Wescott, E. M.: Red sprites and blue jets: Thunderstorm-excited optical emissions in the stratosphere, mesosphere, and ionosphere, Phys. Plasmas, 2, 2514-2522, 1995.

Seyler, C. E., Rosado-Román, J. M., and Farley, D. T.: A nonlocal theory of the gradient-drift instability in the ionospheric E-region plasma at mid-latitudes, J. Atmos. Sol.-Terr. Phy., 66, 1627-1637, 2004.

Shao, X. M., Lay, E. H., and Jacobson, A. R.: Reduction of electron density in the night-time lower ionosphere in response to a thunderstorm, Nat. Geosci., 6, 29-33, 2013.

Sharma, D. K., Rai, J., Israil, M., Subrahmanyam, P., Chopra, P., and Garg, S. C.: Enhancement in ionospheric temperatures during thunderstorms, J. Atmos. Sol.-Terr. Phy., 66, 51-56, 2004.

Shibata, Y., Nagasawa, C., Abo, M., Maruyama, T., Saito, S., and Nakamura, T.: Lidar Observations of Sporadic Fe and Na Layers in the Mesopause Region over Equator, J. Meteorol. Soc. Jpn., 84A, 317-325, 2006.

Shukla, P. K. and Mamun, A. A.: Introduction to Dusty Plasma Physics, Institute of Physics Publishing, Bristol and Philadelphia, 6-7, 2002

Su, H. T., Hsu, R. R., Chen, A. B., Wang, Y. C., Hsiao, W. S., Lai, W. C., Lee, L. C., Sato, M., and Fukunishi, H.: Gigantic jets between a thundercloud and the ionosphere, Nature, 423, 974-976, 2003.

Suparta, W. and Fraser, G. J.: A New Method to Correlate a Possible Coupling between the Upper and the Lower Atmosphere, American Journal of Applied Sciences, 9, 894-901, 2012.

Surkov, V. V., Hayakawa, M., Schekotov, A. Y., Fedorov, E. N., and Molchanov, O. A.: Ionospheric Alfvén resonator excitation due to nearby thunderstorms, J. Geophys. Res., 111, A01303, https://doi.org/10.1029/2005JA011320, 2006.

Takahashi, T., Nozawa, S., Tsuda, T. T., Ogawa, Y., Saito, N., Hidemori, T., Kawahara, T. D., Hall, C., Fujiwara, H., Matuura, N., Brekke, A., Tsutsumi, M., Wada, S., Kawabata, T., Oyama, S., and Fujii, R.: A case study on generation mechanisms of a sporadic sodium layer above Troms $\left\{0\left(69.6^{\circ} \mathrm{N}\right)\right.$ during a night of high auroral activity, Ann. Geophys., 33, 941-953, https://doi.org/10.5194/angeo-33-941-2015, 2015.

Tinsley, B. A.: Influence of Solar Wind on the Global Electric Circuit, and Inferred Effects on Cloud Microphysics, Temperature, and Dynamics in the Troposphere, Space Sci. Rev., 94, 231-258, 2000.
University of Science and Technology of China: The sodium density in the MLT region of sodium temperature and wind lidar over Hefei, V1.0, National Space Science Data Center [data set], https://doi.org/10.12176/01.05.026, 2011.

Voiculescu, M., Aikio, A. T., Nygrén, T., and Ruohoniemi, J. M.: IMF effect on sporadic-E layers at two northern polar cap sites: Part I - Statistical study, Ann. Geophys., 24, 887-900, https://doi.org/10.5194/angeo-24-887-2006, 2006.

von Zahn, U., von der Gathen, P., and Hansen, G.: Forced release of sodium from upper atmospheric dust particles, Geophys. Res. Lett., 14, 76-79, 1987.

von Zahn, U., Goldberg, R., Stegman, J., and Witt, G.: Doublepeaked sodium layers at high latitudes, Planet. Space Sci., 37, 657-667, 1989.

Wakabayashi, M. and Ono, T.: Multi-layer structure of mid-latitude sporadic-E observed during the SEEK-2 campaign, Ann. Geophys., 23, 2347-2355, https://doi.org/10.5194/angeo-23-23472005, 2005.

Wan, W., Liu, L., Parkinson, M. L., Liu, R., He, L., Breed, A. M., Dyson, P. L., and Morris, R. J.: The effect of fluctuating ionospheric electric fields on Es-occurrence at cusp and polar cap latitudes, Adv. Space Res., 27, 1283-1288, 2001.

Wang, C.: New Chains of Space Weather Monitoring Stations in China, Space Weather, 8, S08001, https://doi.org/10.1029/2010SW000603, 2010.

Wilkinson, P. J., Szuszczewicz, E. P., and Roble, R. G.: Measurements and modelling of intermediate, descending, and sporadic layers in the lower ionosphere: Results and implications for global-scale ionospheric-thermospheric studies, Geophys. Res. Lett., 19, 95-98, 1992.

Williams, B. P., Croskey, C. L., She, C. Y., Mitchell, J. D., and Goldberg, R. A.: Sporadic sodium and E layers observed during the summer 2002 MaCWAVE/MIDAS rocket campaign, Ann. Geophys., 24, 1257-1266, https://doi.org/10.5194/angeo-24-12572006, 2006.

Wuhan Geomagnetic Station: Hubei Province Earthquake Administration, Observation data of atmospheric electric field mill at Wuhan Geomagnetic Station, Wuhan, V1.0, National Space Science Data Center [data set], https://doi.org/10.12176/01.05.065, 2010.

WWLLN: World Wide Lightning Location Network, available at: http://wwlln.net/, last access: 6 August 2021.

Yu, B., Xue, X., Lu, G., Ma, M., Dou, X., Qie, X., Ning, B., Hu, L. H., Wu, J., and Chi, Y.: Evidence for lightning-associated enhancement of the ionospheric sporadic E layer dependent on lightning stroke energy, J. Geophys. Res.-Space, 120, 9202 9212, 2015.

Yu, B., Xue, X., Lu, G., Kuo, C. L., Dou, X., Gao, Q., Qie, X., Wu, J., Qiu, S. C, and Chi, Y.: The enhancement of neutral metal Na layer above thunderstorms, Geophys. Res. Lett., 44, 9555-9563, 2017.

Yuan, T., Feng, W., Plane, J. M. C., and Marsh, D. R.: Photochemistry on the bottom side of the mesospheric Na layer, Atmos. Chem. Phys., 19, 3769-3777, https://doi.org/10.5194/acp19-3769-2019, 2019.

Zhang, L., Tinsley, B., and Zhou, L.: Low Latitude Lightning Activity Responses to Cosmic Ray Forbush Decreases, Geophys. Res. Lett., 47, e2020GL087024, https://doi.org/10.1029/2020GL087024, 2020. 
Zhang, Y., Wu, J., Guo, L., Hu, Y., Zhao, H., and Xu, T.: Influence of solar and geomagnetic activity on sporadic-E layer over low, mid and high latitude stations, Adv. Space Res., 55, 1366-1371, 2015.

Zhou, Q. and Mathews, J. D.: Generation of sporadic sodium layers via turbulent heating of the atmosphere?, J. Atmos. Terr. Phy., 57, 1309-1315, https://doi.org/10.1016/0021-9169(95)97298-I, 1995.
Zhou, Q., Mathews, J. D., and Tepley, C. A.: A proposed temperature dependent mechanism for the formation of sporadic sodium layers, J. Atmos. Sol.-Terr. Phy., 55, 513-521, 1993. 